\title{
Complications of proximal humeral fractures
}

\author{
Alessandra Maresca, Letizia Senesi, Simone Cerbasi, \\ Raffaele Pascarella \\ Orthopaedic and Traumatology Unit, Riuniti Hospital, Ancona, Italy
}

Received: March 12, 2021

Accepted: March 22, 2021

Correspondence

Letizia Senesi

Orthopaedic and Traumatology Department, Riuniti Hospital, via conca 71, 60021 Ancona, Italy

E-mail: letizia.senesi@gmail.com

\section{Conflict of interest}

The authors have no conflict of interest to declare.

How to cite this article: Maresca A, Senesi L, Cerbasi S, et al. Complications of proximal humeral fractures. Lo Scalpello Journal 2021;35:2026. https://doi.org/10.36149/0390-5276-201

(C) Ortopedici Traumatologi Ospedalieri d'Italia (O.T.O.D.I.) 2021

\section{(c) (1) () $\Theta$}

This is an open access article distributed in accordance with the CC-BY-NC-ND (Creative Commons Attribution-NonCommercial-NoDerivatives 4.0 International) license. The article can be used by giving appropriate credit and mentioning the license, but only for non-commercial purposes and only in the original version. For further information: https://creativecommons.org/licenses/by-nc-nd/4.0/deed.en

\section{SUMMARY}

Objective. Proximal humeral fractures are among the most frequent fracture in the adult and their treatment is controversial.

The purpose of this paper is to present the most common complications in managing proximal humeral fractures, reviewing the literature.

The principal complications are mainly caused by biological elements, but are also related to iatrogenic factors.

Conclusions. It is very important to provide a correct fracture classification, accurate patient clinical investigation, and to perform all instrumental procedures required to get a correct indication in managing proximal humeral fracture. In case of operative treatment, accurate pre-operatory planning is mandatory. Moreover, the surgeon must consider the feasible intra-operatory complications, such as the possibility to convert an open reduction and internal fixation to a total arthroplasty.

In our opinion, the arthroplasty system should be available in every operating theater.

Key words: humeral fracture complications, proximal humerus fractures, osteonecrosis, nonunion

\section{Introduction}

Proximal humeral fractures (PHF) represent approximately 6\% of all adult fractures ${ }^{1}$ and are among the three most common fracture seen in elderly patients ${ }^{2}$ as 'fragility fractures'. Their incidence has progressively increased because of aging population ${ }^{3-5}$. Approximately $70 \%$ of these fractures occur in patients over 60 years of age, with the highest reported incidence among individuals with 80 years or more $^{6}$.

PHF generally occur in elderly women, with nearly $90 \%$ happening as a result of low energy fall ${ }^{7}$ because of decreased bone density mass. Younger patients generally sustain PHF after high-energy trauma, and account for the remaining fractures of this type ${ }^{8}$.

Almost $75 \%$ of PHF can be treated nonoperatively with good functional results as nearly $50 \%$ are nondisplaced or Neer one-part fractures ${ }^{7}$. However, the treatment for the remaining part of PHF is still controversial ${ }^{9,10}$. In fact, while operative treatment (with open reduction and internal fixation ORIF) is generally recommended for displaced fractures in young and active patients even if older than 60 years ${ }^{7}$, the appropriate treatment in the elderly population is still debated.

In literature there is no significant difference between operative and nonoperative treatment in terms of clinical outcomes. The PROFHER trial recently demonstrated that surgery was not superior to non-operative treatment in managing displaced proximal humeral fractures ${ }^{11}$. 
Moreover, in recent randomized trials ${ }^{12,13}$, nonoperative treatment has been compared with ORIF for treatment of three-part fractures and with hemiarthroplasty for the treatment of fourpart fractures. Although there have been some substantial improvements in operative treatment, the clinical importance of these enhancement is debatable.

This is caused by significant morbidity and high complication rates associated with this condition that mainly regards the most complex pattern of fractures. Moreover, the complication rate of PHF is $22.1 \%$ (range $0-79 \%$ ) ${ }^{14}$.

The main complications are consequent to incorrect indication of conservative/operative treatment, avascular necrosis of the humeral head (13\%) caused by mechanical and biological failure ${ }^{15-17}$, inappropriate surgical technique (40\%) ${ }^{18}$, infections (1-4.5\%) ${ }^{16,19,20}$, nonunion, malunion systemic conditions such as pulmonary embolism $(5 \%)^{21}$, and multifactorial failures such as further trauma.

The failure rate considerably increased with the number of risk factors. The failure rate was $71.4 \%$ in patients with 4 risk factors, and $85.7 \%$ patients with 3 risk factors. The following parameters were found to have a significant influence in the failure rate: age, anatomic reduction and restoration of medial cortical support.

The aim of the present paper is to present the principal complications in operative and nonoperative PHF treatment, reporting our experience and reviewing the literature ${ }^{22}$.

\section{Complications}

\section{Incorrect indication of conservative/operative treatment}

The correct indication in PHF is related to type of fracture, type of patient, status of the patient, and patient's expectation of functional recovery. The surgeon's task is consider all these aspects to recommend the best personalized treatment, individualized for each patient. On occasion, a fixation device is unsuitable for a specific fracture pattern (Fig. 1A-D).

\section{Avascular necrosis of the humeral head}

Avascular necrosis of humeral head (AVNHH) is often associated with a complex pattern of proximal humeral fractures (type III, IV according to Neer's Classification).

Hertel et al. ${ }^{23}$ retain that the AVNHH rate on PHF is linked to the postero-medial metaphyseal extension, residual medial hinge integrity, humeral head rotation, greater tuberosity dislocation over 8-10 mm, humeral head split fractures, and amount of fracture fragments.

However, the main critical aspect is medial calcar integrity. Several studies reveal the influence of this in humeral head blood supply, especially in four-part fractures ${ }^{24}$.

In addition, a head-shaft displacement $>4 \mathrm{~mm}$ was found to be associated with a significantly higher rate of AVNHH, proba- bly as a result of displacement-induced periosteum (and vessels) stripping around the anatomical neck ${ }^{25}$.

AVNHH is the main complication in patients undergoing ORIF surgical technique ${ }^{26}$ and can have both early (6 month after trauma) and late onset ${ }^{27}$.

Recently, it has been demonstrated that risks factors like alcohol ingestion, and age and time to surgery had no influence on the AVNHH rate, while a significant association was found with smoking ${ }^{27}$. Moreover, AVNHH affects typically older patients who showed a higher rate of screw cutout with intraarticular transmigration, associated with nonunion. Even if the incidence of avascular necrosis varies from $0-68 \%$ in literature ${ }^{28-30}$, a recent paper indicated an AVNHH rate of $16.2 \%{ }^{27}$. The surgical treatment of choice in this setting is shoulder arthroplasty ${ }^{25}$.

\section{Biological failure/nonunion}

Biological factors are related to poor bone stock, a very common state in elderly patients or in osteoporotic disease ${ }^{7}$. Moreover, other elements are critical such as medial hinge interruption and fragmentation.

Osteoporosis does not allow a suitable grip of mechanical screws. Moreover, it can lead to excessive difference in stiffness between the plate itself and bone that collapses causing fixation system failure.

Medial hinge fragmentation can implicate varus deformity and failure osteosynthesis with mobilization or breaking plate. Moreover, a multi-fragmentary fracture should be treated with care in order to preserve vascular supply and avoid fragment devascularization (Fig. 2).

\section{Mechanical failure/nonunion}

Mechanical failures are usually related to incorrect fracture reduction, wrong plate positioning, loss of fracture reduction, and incorrect managing of fixation device.

The prevalence of humeral head malunion and non-union is between 1.7 and $13 \%$, depending on the fracture type ${ }^{15,26-28}$. A recent study found a non-union rate of $13 \%{ }^{26}$. Although several factors such as severe displacement, soft-tissue interposition, early mobilization and poor anatomical reduction have been suggested to promote non-union, it seems to remain a multifactorial problem ${ }^{22,31}$. Some risk factors such as age, female sex, smoking, and osteoporosis causing loss of fixation have been described in the literature ${ }^{22,32}$.

Fracture reduction must be controlled both in antero-posterior and oblique X-ray views. It is fundamental to avoid varus deformity, the gap between fractures fragments, and to achieve anatomical fracture reduction. Wrong positioning of the fixation device often leads to incorrect fracture reduction. In ORIF fixation, the length of screws is crucial. In fact, to obtain a suitable grip they must arrive at subchondral bone without overstepping the articular surface. 


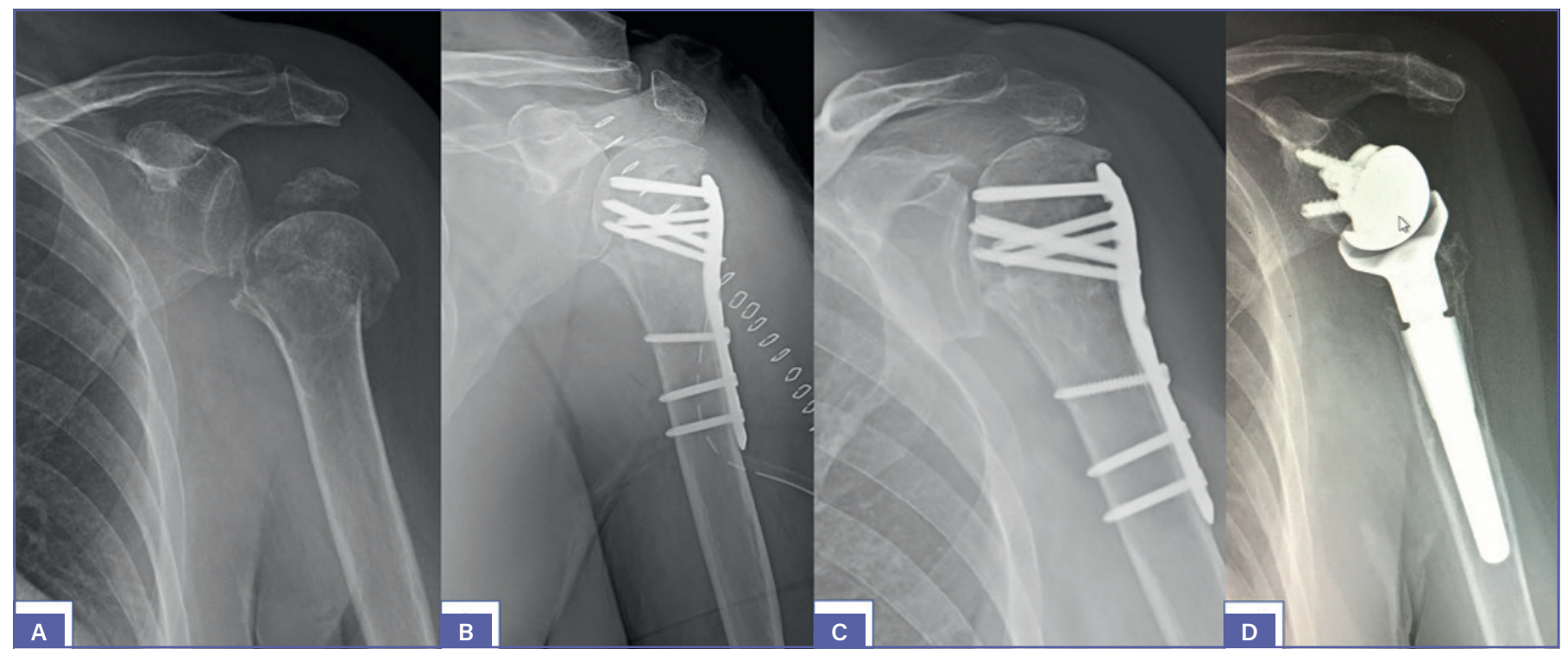

Figure 1. A) Women of 73 y/o reporting a multi-fragmentary proximal humerus fracture; $B$ ) post-operatory $x$-rays: ORIF with inadequate fracture reduction of head displacement and medial cortex; C) X-rays at 8 months after surgery show nonunion with initial necrosis of the humeral head; D) Indication to total shoulder arthroplasty.

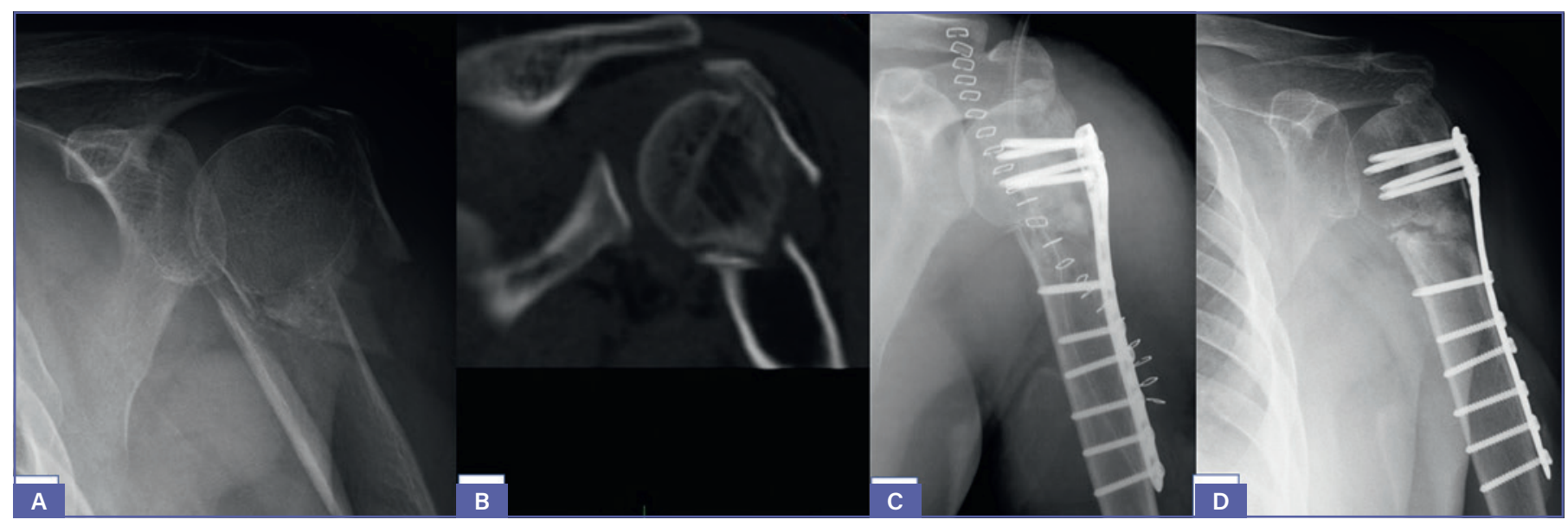

Figure 2. A,B) Female of $67 \mathrm{y} / \mathrm{o}$ with a proximal humerus fracture; C) ORIF technique incomplete medial cortical reduction and loss bone stock; D) 7 months after treatment: fracture nonunion, due probably to excessive construct stiffness (there are too much screw in the proximal site of the fracture).

It is also important to implant a plate of proper length. One of the main problems in metadiaphyseal fracture is related to screw diameter, which is $3.5 \mathrm{~mm}$ in all plate systems.

Sometimes in metadiaphyseal or bifocal fracture of the humerus this screw diameter will not have a valid grip ${ }^{33}$.

Regarding other fixation devices: humeral nail system must be locked distally to avoid fracture fragment collapse and consequent loss of reduction. External fixation or K-wires do not always guarantee good fracture stability and acceptable fracture reduction because of percutaneous access.
The loss of fracture reduction, often within two months after surgery, is usually caused by the aforementioned conditions (Fig. 3).

\section{Inappropriate surgical technique}

Risk of complications are often associated with older age, compromised bone quality, fracture complexity, loss of reduction, implant loosening or breakage, and bone ischemia. According to Konrad et al. ${ }^{18} 40 \%$ of complications occur because of in- 


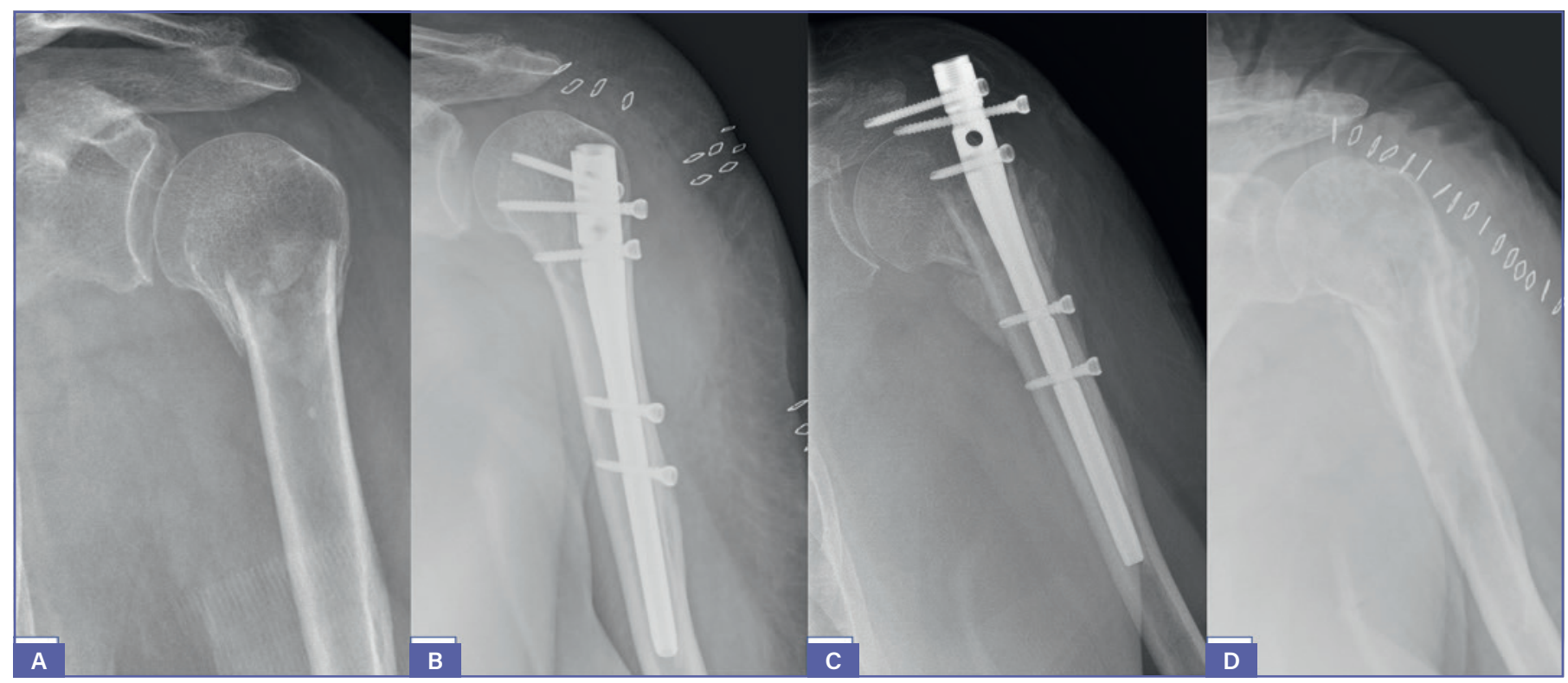

Figure 3. A) Proximal humeral fracture of $91 \mathrm{y} / 0$ woman; B) Post-operatory x-rays after Intramedullary nailing; C) Three months after surgery the patient fall from the stairs and report a nail displacement. Planning was: nail removal and to perform ORIF; D) post-operatory x-rays: after nail removal the fracture appear stable enough. Therefore, we opted to not proceed with ORIF.

correct surgical technique. Moreover, according to Ruchholtz et al. ${ }^{34}$ the complication rate depends on the level of the surgeon's experience.

Inadequate surgery includes implant malposition, insufficient (bad) reduction, lack of bony defect filling, and missing tuberosity reinsertion.

Implant malposition such as too high plate positioning can induce impingement and pain. However, a low plate position can also lead to inadequate head support. In the instance of a large bony head deficiency, the insufficient or lack of autologous bone or homologous graft/synthetic graft can cause head collapse (Fig. 4). Missing tuberosity reinsertion causes a very important limitation of range of motion.

\section{Infections}

Infection is a common complication related to the surgical procedure. In literature the rate of infection changes from 1.1 to $4.5 \%{ }^{16,19,20}$.

A recent paper reported the incidence of acute infection rate to $4 \%{ }^{35}$.

The authors showed that preoperative skin scrubbing with chlorhexidine, type of antibiotic prophylaxis (first generation cephalosporine), and length of surgery most affected the rate of deep infection. This is also our opinion. On the other hand, age, comorbidities, concomitant fractures, gender, type of fixation, and type of reduction (open vs closed) did not significantly affect the rate of infection ${ }^{35}$ (Fig. 5).

\section{Systemic conditions}

Among systemic conditions, pulmonary embolism seems to be the most common side effect following PHF operative treatment, with an incidence of $5 \%{ }^{21}$. No difference in outcomes between type of surgical treatment has been found after either ORIF or arthroplasty. Therefore, chemoprophylaxis to prevent thromboembolic events should be considered in this type of surgery.

\section{Discussion and conclusions}

PHF exhibit a considerable percentage of complications, caused either by fracture type and complexity or by incorrect fracture reduction and fixation. Nowadays, in the literature there is no consensus concerning optimal treatment for PHF, leading to substantial variation in fracture treatment ${ }^{1,13}$. There is now high-quality evidence demonstrating that surgery is not superior to non-operative treatment in the management of PHF, while the complication rate and costs associated with surgery are significantly higher ${ }^{11,36}$.

Currently, the general recommendation is to treat almost all fractures (excluding dislocations) nonoperatively for physiologically older patients, with ORIF for physiologically younger and active patients, and with reverse shoulder arthroplasty when reconstruction is unable ${ }^{37}$. Personalization of treatment is key to provide a correct operative or nonoperative indication. It is mandatory to evaluate the type of patient, age, functional requirements, general conditions, and associated comorbidity, 


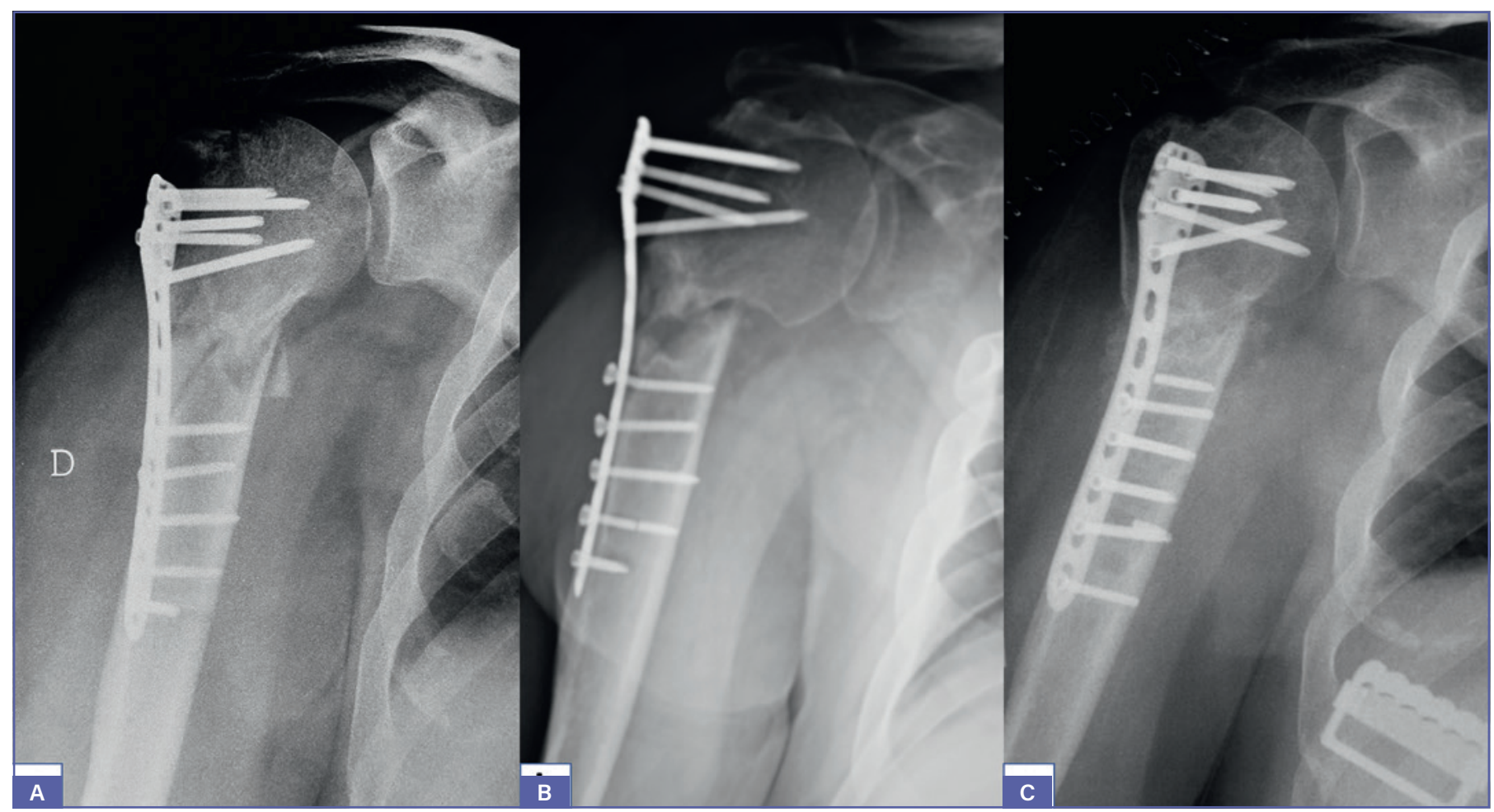

Figure 4. A) 48 y/o young man with proximal humerus fracture, treated with ORIF in other hospital; B) Six months after trauma, X-ray shows implant displacement; C) A new surgical procedure was performed with ORIF.

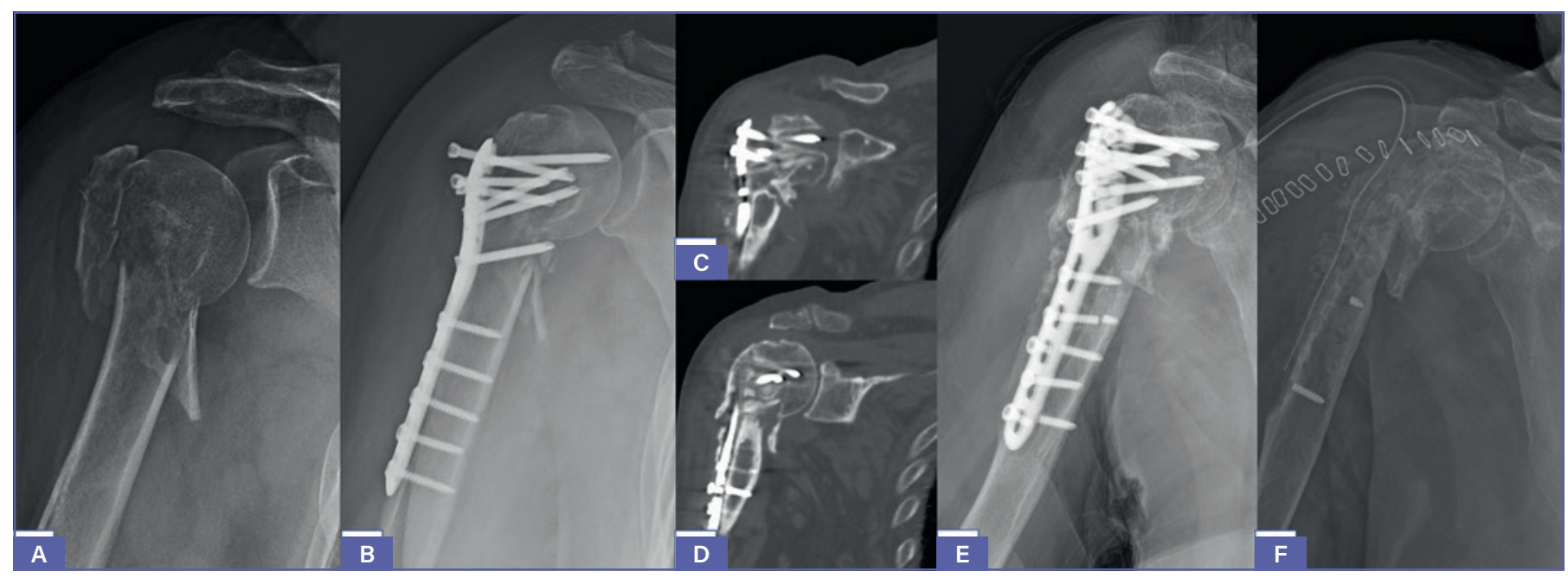

Figure 5. A) 83 y/o woman with multi-fragmentary proximal humerus fracture. ORIF in other hospital; B) Post-operatory X-rays 2 month after surgery revealed initial implant mobilization with screw cut-out; C,D) CT scan reveals in detail the implant and screw mobilization associated with initial humeral head resorption; E) Infection of the implant at 9 months after surgery; F) Implant removal, toilette, and debridement.

quality of life, the patient's expectation of functional recovery, and final outcome. Correct pre-operatory planning of the fracture with correct X-ray views and 3D CT reconstruction is imperative. When the fracture needs to undergo operative treatment, it is very important to choose the right fixation device considering the surgeon's skills, features of the fixation 
device, and estimation of bone stock status. The objective of surgical treatment is to achieve the best anatomical reduction using screws which guarantee good stability and to obtain medial hinge reconstruction.

We believe that in order to avoid major complications it is mandatory to perform careful instrumental investigation and proper surgical technique with realization of the surgeon's limits. Most of complications are related to specific features of fractures and thus it is suitable to have a prosthesis available in the operating room.

\section{Acknowledgements}

Authors are grateful to CSAL Linguistic Center of Ancona for revise the English text.

\section{References}

1 Court-Brown CM, Caesar B. Epidemiology of adult fractures: a review. Injury 2006;37:691-697. https://doi.org/10.1016/j. injury.2006.04.130

2 Barrett JA, Baron JA, Karagas MR, et al. Fracture risk in the U.S. Medicare population. J Clin Epidemiol 1999;52:243-249. https:// doi.org/10.1016/s0895-4356(98)00167-X

3 Kannus P, Palvanen M, Niemi S, et al. Rate of proximal humeral fractures in older Finnish women between 1970 and 2007. Bone 2009;44:656-659. https://doi.org/10.1016/j.bone.2008.12.007

4 Ong T, Sahota O, Marshall L. Epidemiology of appendicular skeletal fractures: a cross-sectional analysis of data from the Nottingham Fracture Liaison Service. J Orthop Sci 2015;20:517-521. https://doi.org/10.1007/s00776-015-0700-1

5 Court-Brown CM, Biant L, Bugler KE et al. Changing epidemiology of adult fractures in Scotland. Scott Med J 2014;59:30-34. https://doi.org/10.1177/0036933013518148

6 Court-Brown CM, Garg A, McQueen MM. The epidemiology of proximal humeral fractures. Acta Orthop Scand 2001;72:365-371. https://doi.org/10.1080/000164701753542023

7 Jawa A, Burnikel D. Treatment of proximal humeral fractures: a critical analysis review. JBJS Rev 2016;4:01874474-20160100000002. https://doi.org/10.2106/JBJS.RVW.O.00003

8 Rothberg D, Higgins T. Fractures of the proximal humerus. Orthop Clin North Am 2013;44:9-19. https://doi.org/10.1016/j. ocl.2012.08.004

9 Bell JE, Leung BC, Spratt KF et al. Trends and variation in incidence, surgical treatment, and repeat surgery of proximal humeral fractures in the elderly. J Bone Joint Surg Am 2011;93:121-131. https://doi.org/10.2106/JBJS.I.01505

10 Court-Brown CM, McQueen MM. The impacted varus (A2.2) proximal humeral fracture: prediction of outcome and results of nonoperative treatment in 99 patients. Acta Orthop Scand 2004;75:736-740. https://doi.org/10.1080/00016470410004111

11 Rangan A, Handoll H, Brealey S, et al.; PROFHER Trial Collaborators. Surgical vs nonsurgical treatment of adults with displaced fractures of the proximal humerus: the PROFHER randomized clinical trial. JAMA 2015;313:1037-1047. https://doi. org/10.1001/jama.2015.1629

12 Boons HW, Goosen JH, van Grinsven S, et al. Hemiarthroplasty for humeral four-part fractures for patients 65 years and older: a ran- domized controlled trial. Clin Orthop Relat Res 2012;470:34833491. https://doi.org/10.1007/s11999-012-2531-0

13 Fjalestad T, Hole MO, Hovden IAH, et al. Surgical treatment with an angular stable plate for complex displaced proximal humeral fractures in elderly patients: a randomized controlled trial. J Orthop Trauma 2012;26:98-106. https://doi.org/10.1097/ BOT.0b013e31821c2e15

14 Gomberawalla MM, Miller BS, Coale RM, et al. Meta-analysis of joint preservation versus arthroplasty for the treatment of displaced 3- and 4-part fractures of the proximal humerus. Injury 2013;44:1532-1539. https://doi.org/10.1016/j.injury.2013.03.030

15 Erasmo R, Guerra G, Guerra L. Fractures and fracture-dislocations of the proximal humerus: a retrospective analysis of 82 cases treated with the Philos $\left({ }^{\circledR}\right)$ locking plate. Injury 2014;45(Suppl 6):S43-48. https://doi.org/10.1016/j.injury.2014.10.022

16 Agudelo J, Schürmann M, Stahel P, et al. Analysis of efficacy and failure in proximal humerus fractures treated with locking plates. J Orthop Trauma 2007;21:676-681. https://doi.org/10.1097/ BOT.0b013e31815bb09d

17 Falez F, Papalia M, Carbone S, et al. Low complication rates in Minimally Invasive Plate Osteosynthesis (MIPO) for proximal humeral fractures at 5 years of follow-up. Injury 2019;50(Suppl 2):S34-S39. https://doi.org/10.1016/j.injury.2019.01.042

18 Konrad G, Bayer J, Hepp P, et al. Open reduction and internal fixation of proximal humeral fractures with use of the locking proximal humerus plate. Surgical technique. J Bone Joint Surg Am 2010;92(Suppl 1 Pt 1):85-95. https://doi.org/10.2106/ JBJS.I.01462

19 Faraj D, Kooistra BW, vd Stappen WAH, et al. Results of 131 consecutive operated patients with a displaced proximal humerus fracture: an analysis with more than two years follow-up. Eur J Orthop Surg Traumatol 2011;21:7-12. https://doi.org/10.1007/ s00590-010-0655-Z

20 Brunner F, Sommer C, Bahrs C, et al. Open reduction and internal fixation of proximal humerus fractures using a proximal humeral locked plate: a prospective multicenter analysis. J Orthop Trauma 2009;23:163-172. https://doi.org/10.1097/ BOT.0b013e3181920e5b

21 Hoxie SC, Sperling JW, Cofield RH. Pulmonary embolism after operative treatment of proximal humeral fractures. J Shoulder Elbow Surg 2007;16:782-783. https://doi.org/10.1016/j. jse.2006.12.004

22 Krappinger D, Bizzotto N, Riedmann S, et al. Predicting failure after surgical fixation of proximal humerus fractures. Injury 2011;42:1283-1288. https://doi.org/10.1016/j.injury.2011.01.017

23 Hertel R, Hempfing A, Stiehler M, et al. Predictors of humeral head ischemia after intracapsular fracture of the proximal humerus. J Shoulder Elbow Surg 2004;13:427-433. https://doi. org/10.1016/j.jse.2004.01.034

24 Brooks $\mathrm{CH}$, Revell WJ, Heatley FW. An anatomical cadaver study. J Bone Joint Surg Br 1993;75:132-136. https://doi. org/10.1302/0301-620X.75B1.8421010

25 Klug A, Wincheringer D, Harth J, et al. Complications after surgical treatment of proximal humerus fractures in the elderly-an analysis of complication patterns and risk factors for reverse shoulder arthroplasty and angular-stable plating. J Shoulder Elbow Surg 2019;28:1674-1684. https://doi.org/10.1016/j.jse.2019.02.017

26 Boesmueller S, Wech M, Gregori M, et al. Risk factors for humeral head necrosis and non-union after plating in proximal humer- 
al fractures. Injury 2016;47:350-355. https://doi.org/10.1016/j. injury.2015.10.001

27 Robinson CM, Stirling PHC, Goudie EB, et al. Complications and long-term outcomes of open reduction and plate fixation of proximal humeral fractures. J Bone Joint Surg Am 2019;101:21292139. https://doi.org/10.2106/JBJS.19.00595

28 Spross C, Platz A, Rufibach K, et al. The PHILOS plate for proximal humeral fractures - risk factors for complications at one year. J Trauma Acute Care Surg 2012;72:783-792. https://doi. org/10.1097/TA.0b013e31822c1b5b

29 Bogner R, Hubner C, Matis N, et al. Minimally-invasive treatment of three- and four-part fractures of the proximal humerus in elderly patients. J Bone Joint Surg Br 2008;90:1602-1607. https://doi. org/10.1302/0301-620X.90B12.20269

30 Solberg BD, Moon CN, Franco DP, et al. Locked plating of 3- and 4-part proximal humerus fractures in older patients: the effect of initial fracture pattern on outcome. J Orthop Trauma 2009;23:113119. https://doi.org/10.1097/BOT.0b013e31819344bf

31 Court-Brown CM, McQueen MM. Nonunions of the proximal humerus: their prevalence and functional outcome. J Trauma 2008;64:1517-1521 . https://doi.org/10.1097/ TA.0b013e3181469840
32 Hernigou J, Schuind F. Smoking as a predictor of negative outcome in diaphyseal fracture healing. Int Orthop 2013;37:883-887. https://doi.org/10.1007/s00264-013-1809-5

33 Maresca A, Sangiovanni P, Cerbasi S, et al. Why a surgically treated humeral shaft became a nonunion: review of 11 years in two trauma centers. Muscoloskelet Surg 2017;101(Suppl 2):105-112. https://doi.org/10.1007/s12306-017-0509-5

34 Ruchholtz S, Hauk C, Lewan U, et al. Minimally invasive polyaxial locking plate fixation of proximal humeral fractures: a prospective study. J Trauma 2011;71:1737-1744. https://doi.org/10.1097/ TA.0b013e31823f62e4

35 Blonna D, Barbasetti N, Banche G, et al. Incidence and risk factors for acute infection after proximal humeral fractures: a multicenter study. J Shoulder Elbow Surg 2014;23:528-535. https://doi. org/10.1016/j.jse.2013.07.058

36 Launonen AP, Lepola V, Flinkkilä T, et al. Treatment of proximal humerus fractures in the elderly: a systemic review of 409 patients. Acta Orthop 2015;86:280-285. https://doi.org/10.3109/17 453674.2014.999299

37 Dean BJ, Jones LD, Palmer AJ, et al. A review of current surgical practice in the operative treatment of proximal humeral fractures: does the PROFHER trial demonstrate a need for change? Bone Joint Res 2016;5:178-184. https://doi. org/10.1302/2046-3758.55.2000596 